\title{
O pensamento de Rita Segato no contexto da violência de gênero à mulher queimada:
} ensaio teórico

\author{
Rita Segato's thinking in the context of gender violence to burnt women: theoretical essay
}

El pensamiento de Rita Segato en el contexto de la violencia de género a las mujeres quemadas: ensayo teórico

Recebido: 19/09/2021 | Revisado: 23/09/2021 | Aceito: 30/09/2021 | Publicado: 02/10/2021

\author{
Mariane Ferreira Barbosa Emerick \\ ORCID: https://orcid.org/0000-0002-3513-8216 \\ Universidade de Brasília, Brasil \\ E-mail: marianefb.emerick@yahoo.com.br \\ Maria Luiza Rêgo Bezerra \\ ORCID: https://orcid.org/0000-0002-3336-7760 \\ 'Universidade de Brasília, Brasil \\ E-mail: marialuizaregobezerra@gmail.com \\ Helena Eri Shimizu \\ ORCID: https://orcid.org/0000-0001-5612-5695 \\ Universidade de Brasília, Brasil \\ E-mail: shimizu@unb.br \\ Katia Torres Batista \\ ORCID: https://orcid.org/0000-0003-1300-4281 \\ Universidade de Brasília, Brasil \\ E-mail: katiatb@terra.com.br
}

\section{Resumo}

Trata-se de um ensaio teórico a partir da tese de Rita Laura Segato no contexto da violência de gênero sofrida pela mulher vítima de queimadura. Para Segato a violência de gênero é a gênese de todas as demais violências e isto traz impactos não somente a mulher vítima, bem como à toda a sociedade que a cerca e na grande maioria das vezes, opina sobre seus corpos, normatiza-os e não atribui o real cuidado que também se espera de toda e qualquer sociedade. Foram elencadas três categorias temáticas a fim de contribuir para o diálogo de Rita Laura Segato e demais autores no contexto supracitado, com vistas à metodologia proposta. Destarte foram listadas as categorias, a saber: 1. Violência de gênero à mulher queimada; 2. A violência de gênero à mulher e as demais violências; 3 . O controle do corpo feminino pela comunidade. Necessita-se de outros estudos com embasamento de mulheres como Rita Segato ao se abordar a violência de gênero contra a mulher.

Palavras-chave: Violência de gênero; Violência doméstica; Mulheres; Queimaduras.

\begin{abstract}
This is a theoretical essay based on Rita Laura Segato's thesis in the context of gender-based violence suffered by burn victims. For Segato, gender violence is the genesis of all other violence and this impacts not only the victim woman, but also the entire society that surrounds her and, in most cases, opines on their bodies, regulates them and not it attributes the real care that is also expected from any and every society. Three thematic categories were listed in order to contribute to the dialogue of Rita Laura Segato and other authors in the aforementioned context, with a view to the proposed methodology. Thus, the categories were listed, namely: 1. Gender violence against burned women; 2. Gender violence against women and other types of violence; 3. Community control of the female body. Further studies based on women such as Rita Segato are needed when addressing gender-based violence against women.
\end{abstract}

Keywords: Gender-based violence; Domestic violence; Women; Burns.

\section{Resumen}

Este es un ensayo teórico basado en la tesis de Rita Laura Segato en el contexto de la violencia de género que sufren las víctimas de quemaduras. Para Segato, la violencia de género es la génesis de todas las demás violencias y esta impacta no solo a la mujer víctima, sino a toda la sociedad que la rodea y, en la mayoría de los casos, opina sobre su cuerpo, lo regula y no le atribuye el verdadero cuidado que le corresponde. también se espera de todas y cada una de las sociedades. Se enumeraron tres categorías temáticas con el fin de contribuir al diálogo de Rita Laura Segato y otros autores en el contexto mencionado, con miras a la metodología propuesta. Así, se enumeraron las categorías, a saber: 1. Violencia de género contra mujeres quemadas; 2. Violencia de género contra la mujer y otros tipos de 
violencia; 3. Control comunitario del cuerpo femenino. Se necesitan más estudios basados en mujeres como Rita Segato al abordar la violencia de género contra las mujeres.

Palabras clave: Violencia de género; Violencia Doméstica; Mujeres; Quemaduras.

\section{Introdução}

Enquanto forte propulsor do mecanismo de poder, o gênero apresenta-se como temática cada vez mais idealizada para discussões a nível mundial, enfatizando a violência de gênero contra a mulher como uma das maiores realidades em diversos países, sejam estes centrais ou periféricos. Ao longo da vida, uma em cada três mulheres, cerca de 736 milhões, são submetidas à violência física ou sexual por parte de seu parceiro ou violência sexual por parte de um não parceiro, estatística esta, praticamente inalterada na última década. Mulheres jovens, entre 15 a 24 anos, são as primariamente acometidas não estando as demais mulheres livres de tal mazela (OMS, 2019; Gomes, 2018)

Nesta ótica, como fiel ativista desta pauta, tem a tese de Rita Laura Segato (2018) que dispõe que a violência de gênero contra a mulher é causadora das demais violências, além de ser o manifesto de um mecanismo de poder acionado e implementado pelo patriarcado, como um dos diversos legados trágicos da colonialidade, com características primárias e essencialmente políticas e não de sobressalência moral. Segato foi escolhida como referencial teórico para este ensaio devido ao seu currículo como antropóloga, feminista conhecida por suas investigações sobre questões de gênero nos povos indígenas e comunidades latino-americanas, sobre violência de gênero e as relações entre gênero, racismo e colonialidade (Segato, 2013;2018;2003).

A violência contra a mulher é atemporal e característica fundamentadora das discussões de gênero no Brasil que ainda seguem por caminhos distantes de resolutividades cabíveis a partir dos reais constructos a serem conceituados e analisados neste universo. De forma peculiar, conforme Borges et al. (2018) tem-se a violência contra a mulher que sofreu queimaduras intencionais em seu corpo, autoinflingidas ou causadas, na grande maioria das vezes, por outro que seja de gênero diferente da vítima, no contexto doméstico e que caracteriza bem a relevância de se determinar conceitos, definições, pontos-chave e políticas resolutivas, combatentes e punitivas desta temática assoladora na realidade brasileira, geradora da perspectiva de um dos piores perfis feminicídas mundiais.

As tipificações de violência física e violência psicológica, são as mais evidentes no contexto da mulher queimada por uma pessoa de outro gênero, pois a mulher encontrar-se-á em uma situação de alteração de sua imagem corporal consequente à agressão também psicológica que ocorrera, tendo em vista o constrangimento, humilhação ridicularização dentre outros fatores que cercearam o processo de queimadura intencional à esta mulher ${ }^{8}$. A vítima sofrerá com sequelas psicológicas, podendo ter sua autoestima devastada, além de sua exposição a problemas de ordem mental. A mulher queimada, vítima de violência, experimenta a queimadura de forma diferente, pois confere um valor negativo às cicatrizes, pois as consideram uma "lembrança" da agressão (Salomoni, 2017; Brasil, 2006; Carboni, 2019; Moreira, 2010).

Nesta ótica este trabalho objetiva descrever a importância de discutir os diversos tipos de violência de gênero, sofridas pela mulher, no contexto brasileiro a partir do pensamento de pesquisadores e ativistas no assunto representado por Rita Laura Segato, sobretudo, pelo "engatinhamento" de tais discussões em um país mormente vivenciador e praticante da colonialidade, em falência e insuficiência de políticas, sobretudo, punitivas aos agressores em questão. Sendo assim tem-se como objetivo apresentar um ensaio-teórico de constructos de Segato no contexto da violência de gênero à mulher queimada.

\section{Metodologia}

Trata-se de um ensaio teórico (Estrela, 2018; Pereira et al., 2018) sobre a violência de gênero a mulher queimada, a partir do pensamento de Rita Laura Segato, a partir de uas obras, a saber: Las nuevas formas de la guerra y el cuerpo de las 
mujeres. In: La guerra contra las mujeres; La nueva elocuencia del poder. In: La escritura en el cuerpo de las mujeres asesinadas en Ciudad Juárez; Patriarcado: Del borde al centro. Disciplinamiento, territorialidad y crueldad en la fase apocalíptica del capital. In: La guerra contra las mujeres;.Las Estructuras Elementales de la Violencia; Gênero e colonialidade: em busca de chaves de leitura e de um vocabulário estratégico descolonial e Antropologia e direitos humanos: alteridade e ética no movimento de expansão dos direitos universais, obras publicadas entre 2003 e 2018 (Meneghetti, 2011).

A partir destas obras foram elencadas tres categorias temáticas, a saber: 1. Violencia de genero à mulher queimada; 2. A violencia de genero à mulher e as demais violencias; 3 . O controle do corpo feminino pela comunidade.

\section{Resultados e Discussão}

Segato (2018) analisa os fenômenos sociais da perspectiva antropológica, onde "até as práticas mais irracionais tem sentido para os seus agentes, obedecem a lógicas que devem ser entendidas a partir do ponto de vista de seus atores sociais que as executam e está convicta que somente mediante a identificação deste núcleo de sentido se pode atuar sobre os atores e suas práticas, aplicar com êxito as ações transformadoras, sejam elas jurídico-policiais, pedagógicas, publicitarias ou de qualquer outro tipo'.

\subsection{Violência de gênero a mulher queimada}

A violência doméstica é aquela praticada ente os membros que habitam um ambiente familiar comum, com o uso da força que resulta em ferimento, tortura ou morte. Pode acontecer entre pessoas com laços de sangue, unidas de forma civil, e subdividida em física, psicológica, sexual, patrimonial e moral. Segundo dados da Central de Atendimento à Mulher da Secretaria de Políticas para as Mulheres da Presidência da República, em 2014, aproximadamente 43\% das mulheres que estão em situação de violência são agredidas diariamente. Em 2015, uma pesquisa feita através do Data Senado revelou que uma em cada cinco mulheres brasileiras já sofreram agressões físicas, seja pelo marido, namorado, companheiro ou ex-companheiro (Diniz, Lopes, Rodrigues, Freitas, 2007).

É um problema de saúde pública, devido aos altos índices, altos custos pessoais, sociais, legais, jurídicos e médicos. A notificação da violência doméstica foi implantada no Sistema de Informação de Agravos de Notificação (SINAN) do Ministério da Saúde em 2009, devendo ser realizada de forma universal, contínua e compulsória nas situações de suspeita de violências envolvendo crianças, adolescentes, mulheres e idosos. Em 2019 foram notificados 289.742 casos, embora todos os tipos de violência estão incluídos neste número ainda existe subnotificação, ou mulheres que não revelaram a agressão, por diversos fatores.

A violência física contra as mulheres pode ser caracterizada por ações como tapas, empurrões, chutes, puxões de cabelo, ameaças com faca, arma de fogo e queimaduras, dentre outras. A queimadura é uma lesão física traumática que acomete o tegumento, podendo ser causada pela interação de agentes térmicos, químicos, elétricos ou radioativos, com consequentes ferimentos mais profundos ocorridos em músculos, tendões e ossos, sendo capaz de causar prejuízos fragmentais ou integrais da pele, além de alterações fisiológicas, metabólicas, hormonais e imunológicos no paciente A lesão por queimadura ainda incapacita e desfigura sua vítima, levando-a a um prolongado período de cuidados médicos. Essa lesão está entre os traumas mais graves, pois, além dos problemas físicos que podem levar a pessoa à morte, também causa desordens psicológicas e sociais (Nielsson, Delajustine, 2020; Gontijo, 2015).

O universo de publicações sobre violência de gênero a mulher é vasto. Existe na literatura muitas publicações, sites do Sistema Único de Saúde, da Organização Mundial de Saúde, Organização Pan Americana de Saúde, Organização das Nações Unidas, apresentando estatísticas, orientações, acolhimento, associações, entre outros. Na base de dados Pubmed foram 
publicados nos últimos 10 anos 5.660 publicações sobre domestic violence women, 33 com as palavras-chave domestic violence women and burn.

Segundo Assis (2012) na revisão de literatura sobre violência contra a mulher e queimaduras no período de 20022012, verificou que o fenômeno da violência doméstica é amplamente estudado na sociedade e que corresponde a $20 \%$ dos atendimentos nos centros de queimaduras. Ademais, em alguns casos as queimaduras em mulheres são autoinflingidas, decorrentes de efeitos da sua história de vida antes da prática de suicídio com comportamento autodestrutivo, representado por: histórias de violência, fragilidade nas relações interpessoais, dificuldades individuais, sofrimento psíquico, distúrbios mentais, entre outros, conforme estudo realizado na região Sul do Brasil investigou a relação entre queimaduras e as tentativas de suicídio, por meio do uso de fogo e seus aceleradores.

Poucos estudos foram relacionados a violência de gênero a mulher queimada, todavia o impacto é de grande importância, marcadas pelo sofrimento diante das queimaduras, as cicatrizes que comprometem a imagem corporal,a autoestima, a relação da mulher de se ver no mundo, problemas sociopsicológicos e a lembrança do trauma e do agressor. Constatou-se nestes estudos a necessidade da abordagem crítica sobre os motivos e consequências desta realidade sob outras perspectivas, antropológicas e sociológicas.

\subsection{A violência de gênero à mulher e as demais violências}

Este tipo de injúria, da queimadura provocada por agressão física, quando interprovocada traz à tona casos monstruosos como o da dentista Cinthya Magaly Moutinho, queimada viva durante um assalto, realizado por três homens, em seu consultório situado no estado de São Paulo no ano de 2013. Cinthya foi queimada por não ter dinheiro naquele local e momento, o que corrobora com o mecanismo de poder imposto e quase que "fator de vida" de muitos seguidores e implementadores do patriarcado. Queimar intencionalmente uma mulher é violar seus direitos humanos, além do evidente descumprimento de leis como a Lei 11.340 de 07 de agosto de 2006, conhecida como "Lei Maria da Penha" (Brasil, 2006) basilar para o levante da pauta da violência contra a mulher com mais intensidade, por mais que ainda careça de maiores aprofundamentos. Assim como Cinthya várias mulheres foram vítimas de queimaduras provocadas em atos de violência, ou por intenção de suicídio na tentativa de se livrar de situações de sofrimento extremo, entre eles de violência doméstica.

Segato (2003) traz nas suas reflexões que a violência contra a mulher tem uma óptica diferente, ampliada, compreendendo o feminicídio como um problema que ultrapassa o gênero, ou seja, é um reflexo de uma sociedade pautada na "pedagogia da crueldade" e que se estende ao corpo feminino, bem como sobre corpos feminizados, ou seja, os corpos passíveis de serem colonizados, conquistados, usurpados, domesticados, apropriados. Essa violência é regida pelo patriarcado colonial moderno de alta intensidade, com o objetivo de eternizar a soberania, o domínio, o poder, como prática de Estado, contra tudo o que o desestabiliza.

A família ocidental encontra-se baseada na ideia de "família pater", herança do direito romano, onde a mulher e os filhos eram vistos como propriedade do homem, mandato da masculinidade, o que Segato ${ }^{2}$ denomina de pedagogia do poder. Essa visão de posse esteve no Código Penal Brasileiro por muitos anos, como ilustra-se o estupro, considerado um crime contra a honra, um ataque contra a dignidade do pai ou marido e não um crime contra o corpo da mulher estuprada, somente 2009 que o crime passou a ser contra a dignidade sexual ${ }^{13}$, ratificando o pensamento de Segato em relação a lentidão do tempo. É nessa semântica do "corpo como território", que visualizamos um ciclo mimético de violência que utiliza o "marcar", com a mulher vítima de violência por queimadura, tem a pele e alma marcada.

Sob este prisma, Rita Segato corrobora que não basta a existência das leis, também se faz necessário que ela seja pedagogicamente divulgada tendo em vista a existência das diversas comunidades morais e do próprio pluralismo moral, visando assim a primária renovação de concepção moral dos sujeitos ali "educados". Prova fidedigna disto é a falsa concepção 
de algumas mulheres de que somente a violência física e sexual configuram violência contra a mulher, quando pela própria Lei Maria da Penha (Brasil, 2006) são descritas outras violências como moral, patrimonial e psicológica, que variam desde ações de ridicularização da mulher, o controle de suas finanças, manipulação e isolamento, ou seja, é importante que haja realmente um trabalho pedagógico e instrucional sobre os tipos de violência contra mulher e características de cada uma.

\subsection{O controle do corpo feminino pela comunidade}

Para Segato (2018) há um equilíbrio e uma proporcionalidade entre a dignidade, a consistência, a força do grupo e a subordinação feminina. A moral do grupo estaria dependente da submissão feminina, e por isso a comunidade busca o controle do corpo feminino. É onde se identifica um dos maiores obstáculos da lei moderna para garantir a autonomia e a igualdade feminina. A liberdade feminina no sistema tradicional baseado no status do homem fragiliza o grupo. Um caso clássico é da "mutilação genital feminina" que representa uma pratica que vitimiza e prejudica a mulher para pertencer ao grupo. Da mesma forma vemos a mutilação provocada pelas queimaduras em casos de violência doméstica, em que o agressor na tentativa de extermínio marca o corpo feminino, irremediavelmente.

Nesta ótica, as normatizações em torno do corpo feminino podem ser consideradas como uma estratégia de controle social que agirá em detrimento deste corpo com vistas ao incentivo de ideologias que suscitem a violência de gênero contra a mulher, ora vulnerável, uma vez que as ações em torno e intracorpo são imputadas à sociedade. É por meio desta premissa que o patriarcado se sobrepõe aos direitos corporais da mulher acarretando assim violências, como as vivenciadas pela mulher que sofreu violência por meio de queimaduras. Ressalta-se que além dos ponteciais distúrbios de imagem corporal ocasionados pelas queimaduras, tem-se o forte impacto psicossocial que tal violência acarreta a mulher vitimada o que também traz à tona a percepção da sociedade com sobressalência da fragilidade da mulher, vista até mesmo como justificativa do ato violento, praticado pelo seu companheiro ou afim, ou seja, foca-se na suscetibilidade feminina e não na absurda ação de seu agressor (Tilio, 2021).

\section{Considerações Finais}

As limitações na identificação de estudos específicos sobre as diversas tipologias de violência contra mulher no Brasil foi um dos pontos para a elaboração deste ensaio-teórico, o que acabou sendo um propulsor para a própria redação do mesmo. Ao tamanho da problemática da violência contra a mulher, deveriam ser proporcionais os levantamentos teóricos-científicos, pesquisas, ensaios, etc. Portanto, incentiva-se que surjam cada vez mais discussões sobre a temática da violência contra mulher, em suas variantes de tipologias: moral, sexual, psicológica e patrimonial, em diversos contextos, saúde, justiça, assistência social, educação e em muitos outros.

Vale ressaltar que Segato considera como importante fator para violência as dificuldades que tem os atores sociais para reconhecer e nominar a violência de gênero, articulada de uma forma quase impossível de subtrair dos hábitos mais arraigados da vida em comunidade e familiar de todos os povos do mundo. Exemplificando que quando se questiona a mulheres se ja sofreram algum tipo de violência doméstica, muitas diriam que não, mas quando especificados os tipos especifico de maus tratos, o número aumenta. Para Segato "No es por decreto, infelizmente, que se puede deponer el universo de las fantasías culturalmente promovidas que conducen, al final, al resultado perverso de la violencia, ni es por decreto que podemos transformar las formas de desear y alcanzar satisfacción constitutivos de un determinado orden socio-cultural, aunque al final se revelen engañosas para muchos. Aquí, el trabajo de la conciencia es lento pero indispensable. Es necesario romoverlo, instigarlo, trabajar por una reforma de los afectos y de las sensibilidades, por una ética feminista para toda la sociedad." 
Nos casos de mulheres vítimas de queimaduras, os maus tratos e agressões provocadas por parceiros em situação de violência doméstica, estão marcados no corpo e não são passiveis de esquecimento ou de confusão. Ressalta-se a singularidade e a forte significância do cerceamento dos pensamentos de Rita Segato para toda e quaisquer discussões relacionadas às questões de gênero, sobretudo no contexto latinoamericano. Ademais, o processo da queimadura, bem como a recuperação da mulher queimada carrega um manto de sofrimento e dor, passando por mudanças na imagem corporal, no estilo de vida e nas relações sociais que pioram a sua condição já violentada, tornando um ciclo negativo que necessita ser modificado.

Assim também se incentiva que as pesquisas relacionadas à violência contra mulher sejam então introduzidas, levantadas e provocadas, cada vez mais, por nós mesmas!

Sugere-se mais estudos sobre a mulher queimada no contexto antropológico, com o intuito de trazer os sentimentos e falas destas mulheres, como forma terapêutica para recuperação da mesma que carrega um manto de sofrimento e dor, passando por mudanças na imagem corporal, no estilo de vida e nas relações sociais que pioram a sua condição ora violentada, proporcionando assim a sua autonomia mesmo diante a um estado de vulnerabilidade acrescida.

\section{Referências}

Assis C. T. S., Sória D. A. C., \& Assis M. R. (2012). A queimadura como ato de violência física contra a mulher: revisão de literatura. Rev bras queimaduras, 11(4):254-258.

B. B. C. (2013) . Brasil: queman viva a dentista al intentar robarla. Bbc/news mundo.

Borges R. T. et al. (2018) O empoderamento da mulher queimada por autoimolação e sua sustentação na religião e espiritualidade. Rev Bras Promoç Saúde, 31(4): 1-7. 10.5020/18061230.2018.8765. https://periodicos.unifor.br/RBPS/article/view/8765/pdf

Brasil. (2006). Lei 11.340 de 07 de agosto de 2006. Dispõe sobre a criação dos juizados de violência doméstica e familiar contra a mulher; altera o código de processo penal, o código penal e a lei de execução penal; e dá outras providências. Brasília, 2006. Http://www.planalto.gov.br/ccivil_03/_ato20042006/2006/lei/111340.htm

Brasil. (2018). Comissão nacional de incorporação de tecnologias no sistema único de saúde (CONITEC). Membrana de biocelulose no tratamento de: lesões cutâneas com perda de pele, úlceras venosas e arteriais, lesões por pressão, queimaduras de segundo grau e áreas doadoras de enxerto. Ministério da saúde, n³28. Http://conitec.gov.br/images/relatorios/2018/relatorio_curativobiocelulose.pdf.

Brasil. (2021). Associação brasileira de defesa da mulher, da infancia e da juventude. (ASBRAD). Significado de violência doméstica. Http://www.asbrad.org.br/violencia-domestica-contra-a-mulher/significado-de-violencia-domestica/

Carboni R. M., et al. (2019). Therapy for patients with burns - an integrating review. Revista da Associação Médica Brasileira, 65(11): 1405 -1412.

Diniz N. M. F., Lopes r. L. M., Fodrigues A. D., \& Freitas D. S. (2007). Mulheres queimadas por maridos e companheiros. Acta paul enferm, 20(3):321-5.

Estrela, C. (2018). Metodologia científica: ciência, ensino, pesquisa. (3a ed.), Editora artes médicas. 2018.

Gomes R., Murta D., Facchini R. \& Meneghel, S. N. (2018). Gênero, direitos sexuais e suas implicações na saúde. Ciência \& Saúde Coletiva, 23(6):19972005. 10.1590/1413-81232018236.04872018. https://doi.org/10.1590/1413-81232018236.04872018.

Gontijo D. C. (2015). Violência pega? Tese (doutorado em bioética) - universidade de Brasília (UNB).

Lima Junior E. M., Barbosa R. C., Teixeira P. R. O., \& Melo F. R. F. (2004). Balneoterapia. In: Maciel, E, Serra M. C, eds. Tratado de queimaduras. Paulo: Atheneu. 421-30.

Meneghetti F. K. (2011) o que é um ensaio teórico? Documentos e debates • rev. Adm. Contemp, 15 (2). 10.1590/s1415-65552011000200010. Https://doi.org/10.1590/s1415-65552011000200010.

Moreira I. C. C. C., Monteiro C. F. S., Magalhães R. L. B., Oliveira A. D. S. \& Melo B. M. S (2010). O enfermeiro diante de situações de violência contra a mulher. in: Leite M. M. I., Martini J. G, Feli V. E. A, orgs. Programa de atualização em enfermagem: saúde do adulto (proenf). Artmed/panamericana, p.87105 .

Nielsson J. G.; \& Delajustine A. C. (2020). A dimensão pública da violência de gênero e a inscrição política do corpo como território: muito mais do que "briga de marido e mulher ". Quaestiu iuris, 13(1), 322-347 10.12957/rqi.2020.40621.

Organização Mundial de Saúde. (2021). Pan American Health Organization (PAHO). Violência contra mulheres. https://www.paho.org/pt/noticias/9-3-2021devastadoramente-generalizada-1-em-cada-3-mulheres-em-todo-mundo-sofre-violencia.

Pereira A. S. et al. (2018). Metodologia da pesquisa científica. Ed. /UFSM.

Salamoni S. S., \& Mass L. D. B. (2017). Mulheres queimadas: uma revisão integrativa de publicações nacionais. Rev Bras Queimaduras, 16(1):34-44. http://www.rbqueimaduras.com.br/details/345/pt-BR/mulheres-queimadas--uma-revisao-integrativa-de-publicacoes-nacionais. 
Research, Society and Development, v. 10, n. 12, e593101220785, 2021

(CC BY 4.0) | ISSN 2525-3409 | DOI: http://dx.doi.org/10.33448/rsd-v10i12.20785

Segato R. L. (2003b), Las Estructuras Elementales de la Violencia. Prometeo.

Segato R. L. (2012). Gênero e colonialidade: em busca de chaves de leitura e de um vocabulário estratégico descolonial », e-cadernos CES. http://journals.openedition.org/eces/1533. 10.4000/ eces.1533.

Segato R. L. (2013). La nueva elocuencia del poder. In: Segato, R. La escritura en el cuerpo de las mujeres asesinadas en Ciudad Juárez. Buenos Aires: Editorial Tinta Limón.

Segato R. L. (2018). Las nuevas formas de la guerra y el cuerpo de las mujeres. In: La guerra contra las mujeres. Prometeo.

Segato R. L. (2018). Patriarcado: Del borde al centro. Disciplinamiento, 5 territorialidad y crueldad en la fase apocalíptica del capital. In: La guerra contra las mujeres. Prometeo.

Segato, R. L. (2006). Antropologia e direitos humanos: alteridade e ética no movimento de expansão dos direitos universais. Mana. 12(1). Https://www.scielo.br/pdf/mana/v12n1/a08v12n1.pdf.

Tilio R., et al. (2021). Corpo feminino e violência de gênero: uma análise do documentário "chega de fiu fiu". Psicologia e sociedade, 33 , e228620. 10.1590/1807-https://doi.org/10.1590/1807-0310/2021v33228620. 